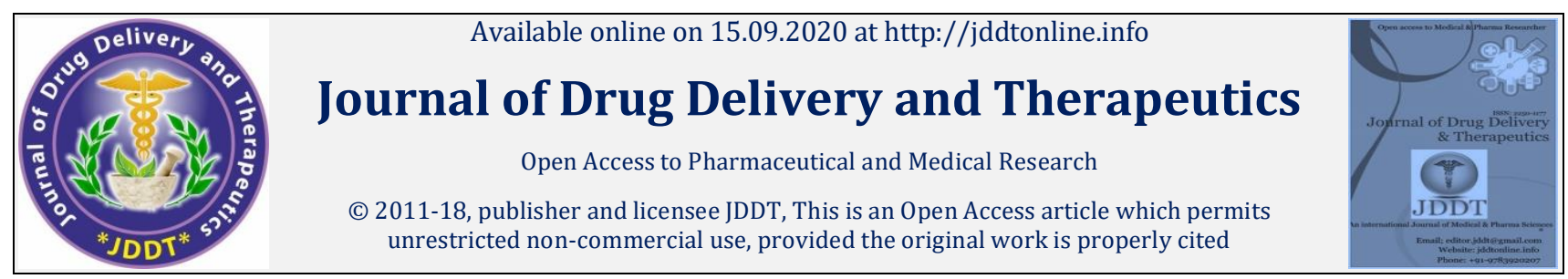

Open@Access

Research Article

\title{
In-vitro anti-malarial activity of Chikadoma plant from the rainforest of Southern Nigeria
}

\author{
Okolo CE ${ }^{1}$, Eban LK², Amazu LU1', Chukwu LC ${ }^{3}$, ${ }^{*}$ Ohadoma SC ${ }^{2}$, Osuala FN ${ }^{4}$ \\ ${ }^{1}$ Department of Pharmacology, College of Medicine, Imo State University, Nigeria \\ 2 Department of Pharmacology, College of Medical Sciences, University of Calabar, Nigeria \\ ${ }^{3}$ Department of Pharmacology, College of Medicine, Chukwuemeka Odumegwu Ojukwu University, Amaku Awka Campus, Nigeria \\ ${ }^{4}$ Department of Pharmacognosy, Faculty of Pharmacy, Madonna University, Elele, Nigeria
}

\begin{abstract}
Background: Malaria remains a life-threatening tropical disease. Due to the development of resistance to the commonly available orthodox antimalarials which of course, poses a great challenge in malaria-controlling-program, alternative and complementary approach becomes imperative thereby making phytotherapy a research focus. Objectives: To investigate the effect of chikadoma plant using its methanol leaf extract against a plasmodium-mediated tropical disease, malaria. Materials and Methods: The culture samples of Plasmodium (P.) falciparum from 20 symptomatic adult outpatients were used in the antimalarial in-vitro test. For cultivation of $P$. falciparum, the culture medium employed was Roswell Park Memorial Institute (RPMI) 1640. Optical microscopy was used for parasite quantification in the performance of antiplasmodial in-vitro assays. The leaf extract of chikadoma dissolved in dimethylsulphoxide (DMSO) was the treatment, prepared into 7 different levels of concentration $(3.125,6.25,12.5,25,50,100$, and $200 \mathrm{mg} / \mathrm{mL})$ while culture medium with the malarial para site alone served as negative control. Micromalarial culture preceded by culture synchronized with sorbitol 5\%, were divided into "control" and "treated groups", followed by incubation in $\mathrm{CO}_{2}$ candle jar at $37^{\circ} \mathrm{C}$ for $72 \mathrm{~h}$. The percentage of parasitemia was measured $8 \mathrm{~h}$, showing the activity of the extract on P. falciparum stages of proliferation. Thin blood smear from the erythrocytes layer was made and stained with $10 \%$ Giemsa for 30 mins to estimate the parasitemia. The antimalarial activity of the extract was calculated using Probit analysis by counting the $50 \%$ growth inhibition $\left(\mathrm{IC}_{50}\right)$. Results: The growth of $P$. falciparum was inhibited by the extract on mature schizont stage; and the IC ${ }_{50}$ of the extract after $40 \mathrm{~h}$ incubation was $3.0 \mathrm{mg} / \mathrm{mL}$. Conclusion: The leaf extract of chikadoma significantly has antimalarial effect in-vitro against P. falciparum.
\end{abstract}

Keywords: Chikadoma; Lupinus arboreus; antimalarial activity; tropical disease; Nigeria.

Article Info: Received 11 July 2020; $\quad$ Review Completed 26 August 2020; Accepted 07 Sep 2020; Available online 15 Sep 2020

Cite this article as:

Okolo CE, Eban LK, Amazu LU, Chukwu LC, Ohadoma SC, Osuala FN, In-vitro anti-malarial activity of Chikadoma plant from the rainforest of Southern Nigeria, Journal of Drug Delivery and Therapeutics. 2020; 10(5):251-254

http://dx.doi.org/10.22270/jddt.v10i5.4322

*Address for Correspondence:

Dr. Ohadoma SC. Department of Pharmacology, College of Medical Sciences, University of Calabar P.M.B 1115 Calabar, Nigeria

\section{INTRODUCTION}

Malaria is caused and mediated by Plasmodium (P.) species. It is one of the tropical diseases with high preponderance of life-threatening, essentially due to emergency of resistance by the causative parasites to most readily available antimalarials, thereby posing serious challenge in roll-back malaria control programs ${ }^{1}$. P. species include P. falciparum, $P$. vivax, $P$. ovale and $P$. malariae, among which $P$. falciparum is perhaps, the most dangerous and widespread, notoriously implicated to cause severe anaemia, kidney failure, hypoglycemia and brain damage particularly among children and infants 2. Important sources of antiprotozoal substances are traceable to plants for development of chemical agents against several tropical diseases. For instance, quinnine is antimalarial of natural origin present in Cinchona spp; artemisinin, limonoids and quassinoids are derived from Artemisia annua, Meliaceae and Simaroubaceae families respectively ${ }^{3}$. Expert opinion has it that from 1981 to 2010, natural products are the origin of approximately $75 \%$ of all the drugs introduced in the past 30 years 4 . Most plants that offer active ingredients for prescription remedy capture the attention of researchers principally because of their application in traditional setting 5. Fortunately, the emergence of European Scientific methods have proven positive pharmacological activity with numerous of the herbal preparations. Nonetheless, a lot of them are used superstitiously and devoid of scientific affirmation or proof. This tendency cuts across various ailments and not particular to folkloric anti-malarials. To buttress this, Khaya 
grandifoliola listed as anaemia remedy 6 has been proven scientifically to lack anti-anaemic effect ${ }^{7}$. Similarly, Zanthoxylum djala-batistae and Xylopia amazonica despite being listed indicating anti-malaria use 8 , have been scientifically disproved to have remedy for malaria ${ }^{9}$. In the rain forest of Southern Nigeria, chikadoma (Lupinus arboreus), Acharatea (cymbopogan citratus), and Ochonyeogwo(Azadiratcha indica) usually prepared as polyherbal mixtures are among several plants acclaimed to possess antimalarial properties by traditional healers. In this regard, some studies have been carried out on Ochonyeogwo 10 and Acharatea 1, but not for chikadoma plants. The objective of this study therefore, was to investigate in- vitro the effect of methanol leaf extract of chikadoma in the treatement of malaria caused by P. falciparum. The plant popularly called "chikadoma" in Nigeria which derived its name after Dr. Chika Ohadoma, a lead researcher who pioneered its novel and extensive study, can be easily recognised as a bushy ornamental shrub up to $1.8 \mathrm{~m}$ tall. It usually has bright yellow smeet-smelling flowers blended with white and purple colours and the English name is Yellow bush ${ }^{11}$. The scientific basis for the therapeutic use of chikadoma highlighted anti-bacterial, antifungal, antiemetic, anti-inflammatory, antineoplastic, antipyretic and antinociceptive activities ${ }^{12}$. Spasmolytic 13 and antiarthritic 14 effects have also been reported. Chikadoma has been shown to contain various phytochemicals which are implicated for its stupendous pharmacological activities such as alkaloids, flavonoids, terpenoids, saponins, glycosides and steroids 15,12

\section{MATERIALS AND METHODS}

\subsection{Plant material}

The fresh leaves of chikadoma were collected from Owerri environs, Nigeria; and authenticated at the Department of Pharmocognosy, Madonna University Elele, Nigeria. The leaves at room temperature were dried for 28 days. After grinding the leaves to fine powder, $2 \mathrm{~kg}$ were extracted using absolute methanol (Sigma Aldrich, Germany) for $48 \mathrm{~h}$. The crude methanol extract (CME) after filtration was concentrated using a rotary evaporator (RV 05 Basic 1B, $1 \mathrm{KA}$, Staufen, Germany) and oven dried further before storing it in a refrigerator until required.

\subsection{Study samples}

In this study, the $P$. falciparum culture samples used originated from 20 symptomatic adult outpatients at Laboratory Unit of Madonna University Teaching Hospital, Nigeria. The necessary study protocols were approved by the appropriate ethical review committee, and informed consent was sort and obtained from all the study participants. With a geometric mean of $0.27 \%$, the parasite densities ranged from 0.01 to $0.95 \%$ infected red blood cells.

\subsection{In-vitro culture}

To establish sensitivities to test isolates with a broad and wide range of drug (antimalarials) susceptibilities, the $P$. falciparum parasite isolates were subjected to culture in the presence of serial dilutions of antimalarials (dihydroartemisimin [DA], mefloquine [MF], chloroquine
[CQ], and quinine [QN] at 1.5\% haematocrit in RPMI 1640 with $0.5 \%$ Albumax 1 [Gibco, Bangkok, Thailand]). The plates were frozen after $72 \mathrm{~h}$ period of culturing, and stored at $20^{\circ} \mathrm{C}$.

\section{4: In-vitro antimalarial assessment}

In this study, a traditional and reliable technique in the assessment of in-vitro antiplasmodial assays which remains parasite quantification by optical microscopy was employed 9. Briefly, the chikadoma extract $(1.0 \mathrm{mg})$ was dissolved in DMSO to make a stock solution of $5.0 \mathrm{mg} / \mathrm{mL}$. Test solutions of the plant extract were prepared via dilution of stock solution in RPMI-1640 culture medium. Antimicrobial activity was conducted in 96 well microculture plates. In microculture plate, $100 \mu \mathrm{L}$ treated drugs were added to each well while $100 \mu \mathrm{L}$ of parasitized culture $(1 \%$ haematocrit, $0.5 \%$ parasitemia) were added to well, and incubated for 72 $\mathrm{h}$ in $\mathrm{CO}_{2}$ candle jar at $37^{\circ} \mathrm{C}$. For the purpose of ascertaining the activities of the extract on the stages of $P$. falciparum growth, the percentage of parasitemia was measured every 8 h. The contents of the various wells were harvested and stained when incubation was concluded. The proliferation stages of parasites were monitored by performing a thin blood smear and stained with Giemsa $10 \%$ for 30 mins. According to Rocha e Silva et al. (2012), all tests were performed in triplicated 16. Using the following formula, parasitemia was calculated after examination under microscope with magnification 1000 by adding immersion oil:

$$
\% \text { Parasitemia }=\frac{\text { Number of infected RBC }}{\text { Total number of RBC }} \times 100
$$

For calculation of percentage of the growth inhibition of the parasites the following formula was employed:

$$
\text { \% Inhibition }=\frac{\text { Parasitemia in control }- \text { parasitemia in treated group }}{\text { Total number of RBC }} \mathrm{X}
$$

At each concentration, growth stages percentage inhibition of the parasites was calculated by the mean of at least three (3) IC 50 viability of parasites in which the $50 \%$ of growth stages of inhibition was calculated by method of Probit analysis.

\subsection{Statistical analysis}

The $\mathrm{IC}_{50}$ values of individual inhibitory concentrations were generated by Probit analysis and non-linear regression using the GraphPad Program (Intuitive Software for Science, San Diego CA, USA).

\section{RESULTS}

The results of in-vitro antimalarial activity of the methanol leaf extract of chikadoma on P. falciparum were obtained. Both the percentages of parasitemia and that of growth stages inhibitory of $P$. falciparum calculated to $72 \mathrm{~h}$ in every $8 \mathrm{~h}$ interval are shown in Tables I and II, respectively. The chikadoma leaf extract inhibited the proliferation of $P$. falciparum on mature schizont stage. The fifty percentage inhibitory concentration ( $\mathrm{IC}_{50}$ ) of the extract by which the antimalarial activity was determined, calculated using Probit analysis was $3.0 \mu \mathrm{g} / \mathrm{mL}$ after $32 \mathrm{~h}$ incubation (Table III). 
Table 1: The percentage of parasitemia after cultivation in $8 \mathrm{~h}$ interval to $72 \mathrm{~h}$ at different concentrations of chikadoma methanol leaf extract

Percentage parasitemia during cultivation

Concentration

$(\mu g / m L)$

\begin{tabular}{lllllllllll} 
& $8 \mathrm{~h}$ & $16 \mathrm{~h}$ & $24 \mathrm{~h}$ & $32 \mathrm{~h}$ & $40 \mathrm{~h}$ & $48 \mathrm{~h}$ & $56 \mathrm{~h}$ & $64 \mathrm{~h}$ & $72 \mathrm{~h}$ \\
\hline 0.000 & 11.04 & 8.17 & 12.70 & 15.90 & 16.22 & 16.36 & 15.70 & 15.92 & 16.40 \\
3.125 & 6.13 & 8.01 & 8.0411 .53 & 9.51 & 11.20 & 14.80 & 13.61 & 11.21 & \\
6.25 & 7.33 & 5.22 & 6.709 .00 & 6.30 & 11.03 & 13.70 & 12.40 & 10.42 & \\
12.5 & 7.02 & 5.04 & 5.607 .12 & 5.80 & 11.71 & 13.02 & 12.20 & 9.10 & \\
25.0 & 5.63 & 3.54 & 5.076 .21 & 5.20 & 9.60 & 12.21 & 11.60 & 7.80 & \\
50.0 & 5.30 & 2.60 & 4.705 .10 & 4.70 & 6.80 & 10.50 & 10.22 & 6.04 & \\
100.0 & 4.25 & 2.23 & 4.304 .04 & 3.40 & 5.52 & 9.20 & 8.20 & 5.60 &
\end{tabular}

Table 2: The percentage of growth inhibition of $P$. falciparum after cultivation in $8 \mathrm{~h}$ interval to $72 \mathrm{~h}$ at different concentrations of chikadoma methanol leaf extract.

Percentage growth inhibition of P. falciparum during cultivation

Concentration

$(\mu g / m L)$

\begin{tabular}{lllllllllll} 
& $8 \mathrm{~h}$ & $16 \mathrm{~h}$ & $24 \mathrm{~h}$ & $32 \mathrm{~h}$ & $40 \mathrm{~h}$ & $48 \mathrm{~h}$ & $56 \mathrm{~h}$ & $64 \mathrm{~h}$ & $72 \mathrm{~h}$ \\
\hline 0.000 & - & - & - & - & - & - & - & - & - \\
3.125 & 27.4 & 25.0 & 37.0 & 27.4 & 41.4 & 32.0 & 6.0 & 15.0 & 32.0 \\
6.25 & 34.0 & 36.1 & 47.4 & 61.4 & 44.0 & 33.0 & 13.0 & 12.40 & 36.4 \\
12.5 & 36.4 & 38.3 & 56.0 & 64.4 & 56.0 & 35.0 & 17.0 & 24.0 & 45.0 \\
25.0 & 49.0 & 57.0 & 60.0 & 68.2 & 61.0 & 41.5 & 22.0 & 27.3 & 52.0 & \\
50.0 & 52.0 & 69.0 & 63.1 & 71.2 & 68.0 & 59.0 & 33.0 & 36.0 & 63.2 \\
100.0 & 62.0 & 73.0 & 66.3 & 79.0 & 75.0 & 66.3 & 42.0 & 49.0 & 65.0 \\
200.0 & 73.0 & 79.2 & 71.0 & 90.0 & 79.0 & 77.0 & 74.0 & 69.0 & 76.1 \\
\hline
\end{tabular}

Where - means no percentage inhibition with negative control

Table 3: The IC50 value against growth of $P$. falciparum after cultivation in $8 \mathrm{~h}$ intervals to $72 \mathrm{~h}$ of $C$. citratus aqueous leaf extract.

\begin{tabular}{lc}
\hline Observation (hour) & $\mathrm{IC}_{50}(\mu \mathrm{g} / \mathrm{mL})$ \\
\hline 8 & 31.7 \\
16 & 19.0 \\
24 & 9.8 \\
32 & 12.1 \\
40 & 3.0 \\
48 & 27.5 \\
56 & 99.0 \\
64 & 92.9 \\
72 & 19.4 \\
\hline
\end{tabular}

\section{DISCUSSION}

From the results obtained in this study, methanol leaf extract of chikadoma plant from the rain-forest of Southern Nigeria possesses antimalarial effect. This may not be unconnected with the presence of phenolic compounds, flavonoids, terpenoids and alkaloids among others 17, 12 which corroborate previous studies that plant extracts containing such phytocompounds do possess antiplasmodial tendencies 18,19. It should be noted that the plethora of phytochemical compositions of Lupinus arboreus varies according to the geographical source and location 20, 21, however, quinolizidine alkaloids are considered as the chemotaxonomical markers of the plant genus and have constantly been registered even in Chikadoma which is located and sourced from the rain-forest region of Southern Nigeria. The presence of alkaloids as a source of potent antimalarial and antiplasmodial substances has been supported by studies on plant species from the Amazon region such as Brazil 22. Phenolic compounds had been reported and implicated in the antiplasmodial and antimalarial activity of husk extract and fractions of Zea 
mays 23 where 8 phenolics have been detected in its ethanol husk extract 24. Gallic acid and Kaempferol are among phenolic compounds implicated in the antimalarial and antiplasmodial activity of plants 25 . In-vitro antimalarial activity in this investigation, was found in the $\mathrm{IC}_{50}=3.0$ $\mu \mathrm{L} / \mathrm{mL}$ of the methanol leaf extract of Chikadoma on mature schizont stage after $40 \mathrm{~h}$ cultivation. This represented a variation to that of the aqueous leaf extract of Azadiratcha indica and Cymbopogan citratus with $\mathrm{IC}_{50}$ of 2.0 and 3.9 $\mu \mathrm{L} / \mathrm{mL}$ respectively 26,1 , indicating higher potency than $C$. citratus but less potency than $A$. indica. In-vitro antimalarial activity of plant extracts could be explained as the synergism of the bioactive components which occur as complexes of structurally related compounds. However, these phytochemicals may exhibit diminished effect in-vivo due to pharmacokinetic parameters (low bioavailability, biotransformation) and physiological factors in the host organism 27. Flavonoids especially, and other antioxidant potentials of some plants which are present in Chikadoma 28 have been known to up-regulate schizonticidal activity through modulation of the cellular signaling pathway 29,23 . This could be speculated as one of the mechanisms of action of Chikadoma recognizing the antioxidant activity of its phenolics and flavonoids, because elevated levels of free radicals which are common features of malaria cases are implicated in malaria complications 24 .

\section{CONCLUSION}

The leaf extract of Chikadoma plant possessed antimalarial activity against $P$. falciparum, in-vitro. This gives credence to the ethnopharmacological use of Chikadoma from the rain forest region of Southern Nigeria for intervention of malaria.

Conflict of Interest: The authors have declared no conflict of interest.

\section{Source of financial support: Nil}

\section{Authors Contributions:}

OCE designed the study, literature search, and draft manuscripts

ELK: Literature search, draft manuscripts.

ALU, OFN, and CLC: Plant material, samples, and bench work

OSC conceptualized and manuscript review. All authors read and approved the final manuscript.

\section{REFERENCES:}

[1] Ohadoma SC, Nnatuanya IN, Osuala FN. Intrinsic activity of aqueous leaf extract of Cymbopogon citratus against plasmodium-mediated tropical disease. Journal of Herbal Medicine Research 2017, 2:17

[2] Sutanto I, Ismid IS, Syraifuddin PK, Sungkar S. Medical Parasitology, 4th ed., Jakarta: Medical Faculty of University of Indonesia Publishers, 2008; p. 221-231.

[3] Schmidt IJ, Khalid SA, Romanha AJ, Alves TMA, Biavatti W, Brun $\mathrm{R}$ et al. The potential of secondary metabolites from plants as drugs or leads against protozoan neglected diseases-part 1. Curr Med Chem. 2012; 19:2128

[4] Newman DJ, Cragg GM. Natural products as sources of new drugs over the 30 years from 1981 to 2010, J Nat Prod. 2012; 75:311.

[5] Schulz V, Hansel R, Tyler VE. Rational phytotherapy. A physician's guide to herbal medicine. Berlin: Springer-Verlag, 1998; p. 5-8.

[6] Adjanohoun E, Ahiyi M, Ake-Assi L, Dramane K, Elewude J, Foduju $\mathrm{S}$ et al. Traditional Medicine and pharmacopoeia contribution to ethnobotanical and floristic studies in Western Nigeria. Lagos: OAU/STRC Publications, 1991; p. 149

[7] Adeyemi AA, Gbolade AA. Anti-anaemic activity of Spondias mombin and Khaya grandifoliola aqueous extracts on rats. J Pharm Biores. 2006; 3(2):94-97.
[8] Isabang N, Fokou PVT, Tchokouaha LRY, Noguem B, Bakamga-via I, Nguefi MSD, et al. Ethnopharmacological survey of Annocaceae medicinal plants used to treat malaria in four areas of Cameroon. J Ethnopharmacol. 2002; 139:171-180.

[9] Lima RBS, Rocha e Silva LF, Melo MRS, Costa JS, Ficanco NS, Lima ES, et al. In-vitro and in-vivo anti-malarial activity of plants from the Brazilian amazon. Malar J. 2015; 14:508.

[10] Yusuf H, Maryatun S. The antimalarial activity of the leaf extract of the Neem leaves (Azadiratcha indica, A. Juss) on Plasmodium falciparum in-vitro. Proceedings of the Annual International Conference Sayiah Kuala University Banda Aceh, Indonesia 2011; p. 217

[11] Pickart AJ, Miller LD. Yellow bush lupin invasion in Northern California coastal dunes. Ecological impacts and manual restriction techniques. Restoration Ecology 1998; 6:59-68.

[12] Ohadoma SC. Scientific basis for the therapeutic use of Lupinus arboreus. Euro J. Pharm Med Res. 2018; 5(3):30-34.

[13] Ohadoma SC, Osuala FN, Nnatuanya IN. Spasmolytic activity of methanol leaf extract of Lupinus arboreus in guinea pig ileum. Euro J. Pharm Med Res., 2016; 3(7):50-52.

[14] Ohadoma SC, Lawal BAS, Chukwu LC. Anti-arthritic activity of methanol leaf extracts of Chikadoma in complete freud's adjunct-induced arthritic rats. British J Med \& Health Sci. 2019; $1(2): 43-46$.

[15] Lough BJ. Isolation and characterization of developing seed of Lupinus arboreus. J Pharmacol, 1992; 12(1):22-26.

[16] Rocha e Silva LF, Magalhaes PM, Costa MR, Alecrim MG, Chaves FC, Hidalgo AF et al. In-vitro susceptibility of Plasmodium falciparum Welch field isolates to infusions prepared from Artemisia annua L. cultivated in the Brazilian Amazon. Mem Insti Oswaldo Cruz. 2012; 107:859-866.

[17] Ohadoma SC, Akuodor GC, Amazu LU, Michael HU. Quantitative estimation of total phenolic and total flavonoid contents of ethylacetate fraction of Chikadoma as a bactericidal agent. Asian J Sci \& Tech. 2020; 11 (6):11012-11014.

[18] Okokon JE, Obot AU, Mohanakrishnan D, Mittal G, Sahal D. Antimalarial and antiplasmodial activity of leaf extract of Alchornea laxiflora. J Herbs Spices Med. Plants 2017; 23 (2):128141.

[19] Khai B, Vlark J, Ling T, Connelly M, Medina-Bolivar F, Rivas F. Antimalarial evaluation of the chemical constituents of hairy root culture of Bixa orellana L. Molecules. 2014; 19:756.

[20] Trease GE. A textbook of pharmacognosy. 9th ed. London: W.B Saunders, 1996; p.201.

[21] Kar A. Pharmacognosy and pharmacobiotechnology, 2nd ed. New Delhi: New Age Publishers, 2007; p. 449.

[22] Torres ZE, Silveira E, Rocha e silva LF, Lima ES, Vasconcellos MC, Uchoa DA, et al. Chemical composition of Aspidosperma ulei Markgr and antiplasmodial activity of selected indole alkaloids. Molecules. 2013; 18:6281-6297.

[23] Okokon JE, Antia BS, Mohanakrishnan D, Sahal D. Antimalarial and antiplasmodial activity of husk extract and fractions of Zea mays. Pharm Biol. 2017; 1394-1400.

[24] Dong J, Cai L, Zhu X, Huang X, Yin T, Fang H, et al. Antioxidant activities and phenolic compounds of corn husk, corn cob and stigma maydis. J Braz Chem Soc. 2014; 25:1956-1964.

[25] Barliana MI, Suradji EW, Abdulah R, Diantini A, Hatabu T, Nakajima-Shimada J, et al. Antiplasmodial properties of kaempferol-3-0-rhamnoside isolated from the leaves of Schima wallachii against chloroquine-resistant Plasmodium falciparum. Biomed Rep. 2014; 2:579-583.

[26] Alshawsh MA. Assessment of antimalarial activity against Plasmodium falciparum and phytochemical screening of some Yemeni medicinal plants 2007. http:/creativecommons.org/lincences/by-ac/12.0/uk

[27] Pereira TB, Rocha e Silva LF, Amorin RC, Melo MR, Souza RC, Eberlin MN, et al. In-vitro and in-vivo antimalarial activity of limonoids isolated from the residual seed biomass from Carapa guianensis (Andiroba) oil production. Malar J. 2014; 13:317.

[28] Ohadoma SC, Eban LK. Antioxidant and free radical scavenger effects of methanol leaf extract of Lupinus arboreus. Euro J. Biomed Pharm Sci. 2018; 5(1):70-73.

[29] Chokchaisiri R, Chaichompoo W, Chalermglin R, Suksamran A. Potent antiplasmodial alkaloids and flavonoids from Dasymaschalon acuminatum. Rec Nat Prod. 2015; 9:243-246. 